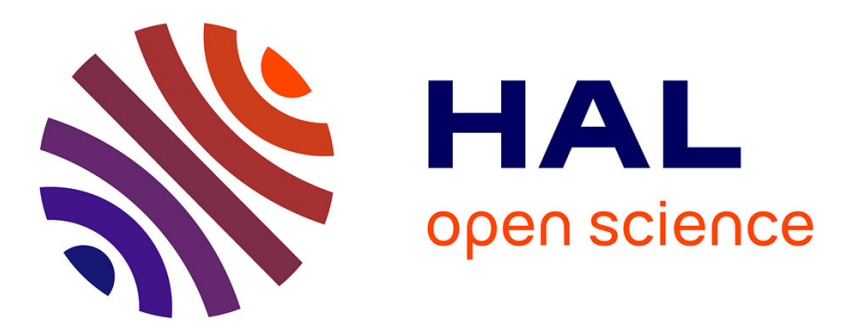

\title{
Evaluation of the deposit dynamics on a gravel bar after different hydrologic events
}

Junjian Deng, B. Camenen, Lionel Pénard, Thomas Drevet

\section{To cite this version:}

Junjian Deng, B. Camenen, Lionel Pénard, Thomas Drevet. Evaluation of the deposit dynamics on a gravel bar after different hydrologic events. River Flow 2020, Jul 2020, Delft, Netherlands. hal03118421

\section{HAL Id: hal-03118421 \\ https://hal.science/hal-03118421}

Submitted on 22 Jan 2021

HAL is a multi-disciplinary open access archive for the deposit and dissemination of scientific research documents, whether they are published or not. The documents may come from teaching and research institutions in France or abroad, or from public or private research centers.
L'archive ouverte pluridisciplinaire HAL, est destinée au dépôt et à la diffusion de documents scientifiques de niveau recherche, publiés ou non, émanant des établissements d'enseignement et de recherche français ou étrangers, des laboratoires publics ou privés. 


\title{
Evaluation of the deposit dynamics on a gravel bar after different hydrologic events
}

\author{
J. Deng, B. Camenen, T. Drevet and L. Pénard \\ INRAE, UR RiverLy, 5 Rue de la Doua, CS 20244, 69625 Villeurbanne Cedex, France
}

\begin{abstract}
Estimating the fine sediment budget in alpine rivers is an important challenge to better understand the morphodynamics of such rivers. In this paper, we describe the dynamics of fine-sediment deposits over a gravel bar before and after two flushing events in an alpine river based on pictures taken from the side of the river. These pictures are processed using a new image analysis method. It allows to estimate the spatial distribution of fine-sediment deposit on the gravel bar using photos taken at different dates. Photos before and after the flushing events in 2018 and 2019 were analysed. Comparison with the local in-situ measurement of surface grain size distribution has been carried out using the Wolman peddle count method. The image detection method presents a good agreement on the spatial distribution and variations of fine sediment deposits on the gravel bar with an acceptable bias. A discussion is provided on the limits and validation of the proposed method as well as on its applicability on medium term analysis.
\end{abstract}

\section{INTRODUCTION}

A significant amount of fine sediments can be found in piedmont gravel bed rivers. Gravel bars represent one of the main zones of storage (Bridge, 1993). It remains however very difficult to estimate the total amount of fine sediment stock on gravel bars since these sediments are easily washed out and can also infiltrate into the gravel matrix. Indeed, it often represents a nonnegligible part of the sediment flux passing through the system (Misset et al., 2019). Moreover, very different dynamics can be observed from one class of sediments to another, i.e. washload of silts versus graded-suspension of sands (Camenen et al., 2016). It is thus a real challenge to provide fine sediment budgets over a system. The purpose of this paper is to present some field experiments describing the dynamics of fine-sediment deposits during two flushing events in an alpine river based on pictures taken from the side of the river (Camenen et al., 2013). Using a new image analysis method based on clustering (presented in section 3, Lloyd, 1982), this paper provides an analysis of fine sediment dynamics (budget and spatial distribution) over a gravel bar after two dam flushing events in 2018 and 2019 (presented in section 4). A discussion of the results is then presented using local measurements of surface grain size distribution before and after a flushing event in 2019.

\section{FIELD MEASUREMENTS}

\subsection{Location of the field measurements}

The Arc en Maurienne River is an engineered alpine river characterised by a nival hydrologic regime and marked by an intense input of fine sediments from the catchment. The total area of the catchment is $1957 \mathrm{~km}^{2}$ at the confluence with the Isère River. The area of interest is a single gravel bar located within a system of alternate bars $9 \mathrm{~km}$ downstream of St-Jean-de-Maurienne (see Figure 1). This reach, which has a mean slope of $0.6 \%$, has been studied since 2005 (Jaballah et al., 2015). One point of interest of this site is that flushing events of the three run-of-the-river dams are conducted yearly in June allowing the performance of in-situ experiments at a specified date known in advance. Topographic, bathymetric and flow measurements are regularly carried 


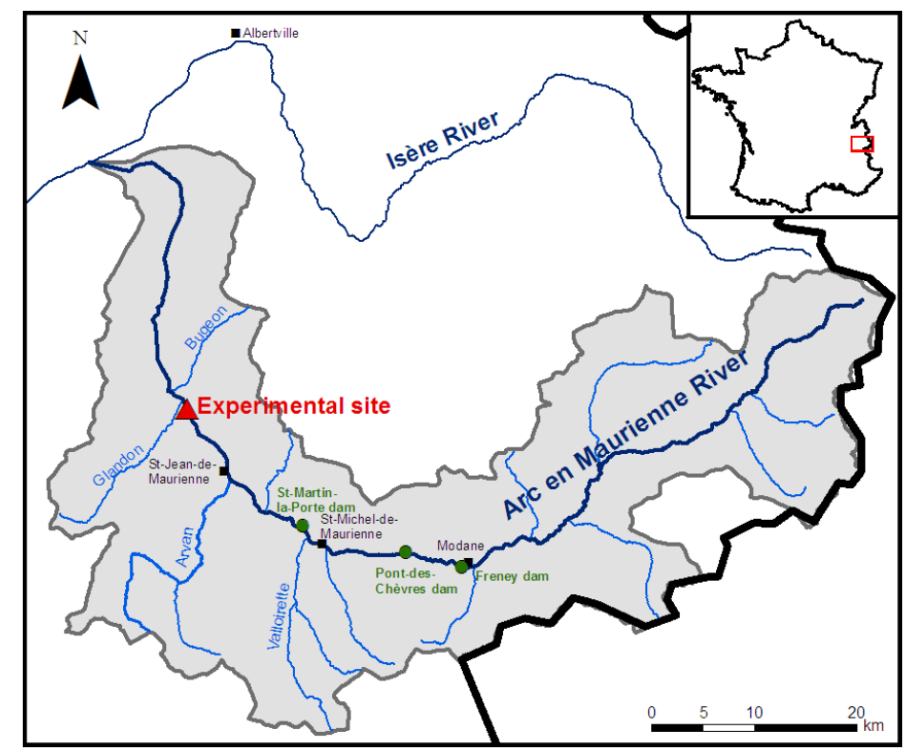

Figure 1. Arc Catchment and location of experimental site (green points correspond to run-of-the-river dams)

out during these flushing events. A focus has been made on the fine sediments dynamics during the flushing events (Antoine et al., 2013, Antoine, 2013, Camenen et al., 2016, Camenen et al., 2018) and the impact of the gravel bar on fine sediment exchange between the bed and the flow appeared to be a significant issue (Camenen et al., 2015).

\subsection{Hydro-sedimentary measurements}

Generally, a flushing event lasts around 12 hours and follows a designed hydrograph with two plateaus, one at $Q \approx 80 \mathrm{~m}^{3} / \mathrm{s}$ and a second one at $Q \approx 150 \mathrm{~m}^{3} / \mathrm{s}$, both approximately lasting 4 hours. The studied gravel bar is totally inundated for a flow discharge $Q \approx 100 \mathrm{~m}^{3} / \mathrm{s}$. During both flushing events in 2018 and 2019, the inundation was clearly photographed by the camera implemented on the side of the river (see Figure 2(b)).

The field campaigns included topographic measurements of the gravel bar before and after the event. A hydro-sedimentary station located $9 \mathrm{~km}$ upstream the study site (at St-Jean-deMaurienne) monitored the fine sediment fluxes. During the previous flushing events, very large concentrations of SSM (Suspended Sediment Matter) were often observed, up to $C_{\max }=30 \mathrm{~g} / 1$ (Antoine, 2013). In 2018, a peak of concentration of $32 \mathrm{~g} / 1$ has been observed during the flush event (see Figure 2(c)). However, in 2019, a high concentration of SSM has been observed 4.5 hours before the flushing event with a peak of $31.5 \mathrm{~g} / 1$, and the peak concentration of the flushing event reached only $\mathrm{C}_{\max }=8.7 \mathrm{~g} / 1$ (see Figure $2(\mathrm{~d})$ ).

\subsection{Local sediment measurement}

Wolman pebble count method (Wolman, 1954) was carried out to measure the surface grain size distribution on the studied gravel bar before and after the flushing event in 2019. Following the instructions of the Wolman method, 5 patches (see Figure 3(a)) were firstly decided. An operator went all over each patch along several backwards and forwards stochastic trajectories, picked up the particle beneath the tip of the toe of the boot and measured the intermediate axis $b$ of this particle by the use of gabarit from the FISP (Federal Interagency Sedimentation Project) US SAH97 model.

A grain size distribution (GSD) analysis from Wolman method samples has been carried out for the flushing event in 2019. In Figure 3(b), the cumulative frequency of GSD for the samples were plotted. Looking at the fine sediment fraction $(\mathrm{d}<10 \mathrm{~mm})$, the frequency GSD shows a decrease of frequency for patch 1 and an increase of frequency for patch 2 . This may be due to the fact that the higher elevation of patch 2 causes a low water depth and low velocities which results in a low bed shear stress and a fine sediment deposition. On the contrary, some fine sediment erosion 


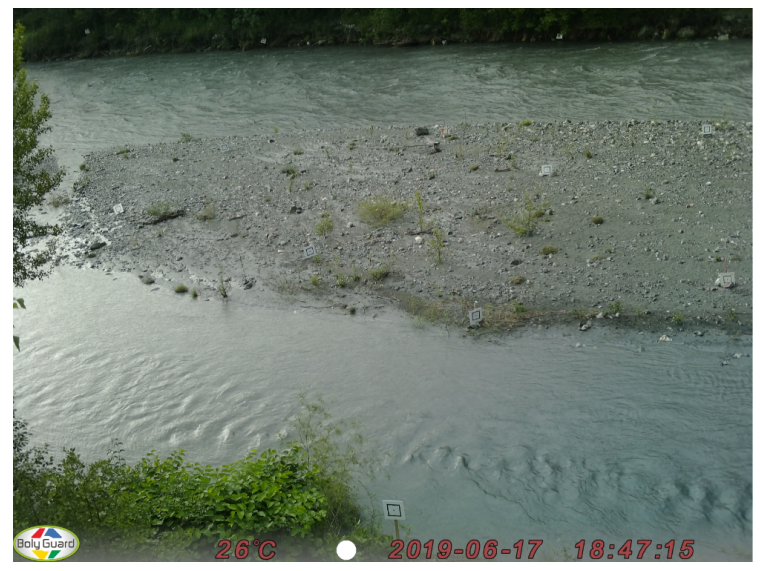

(a)

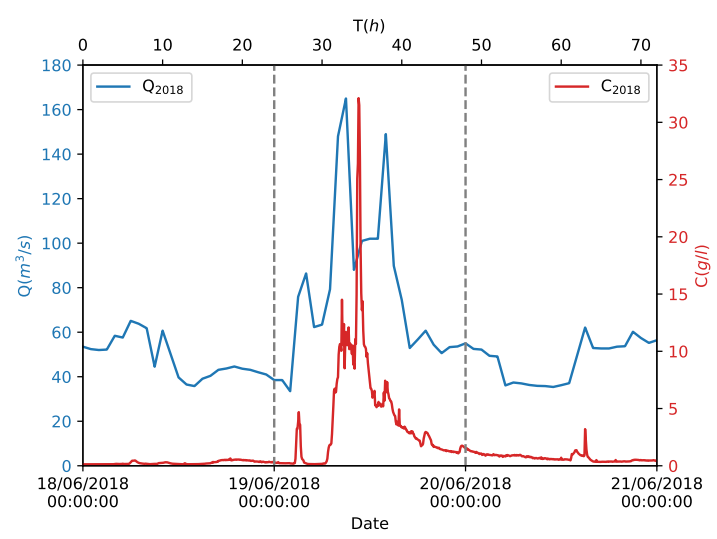

(c)

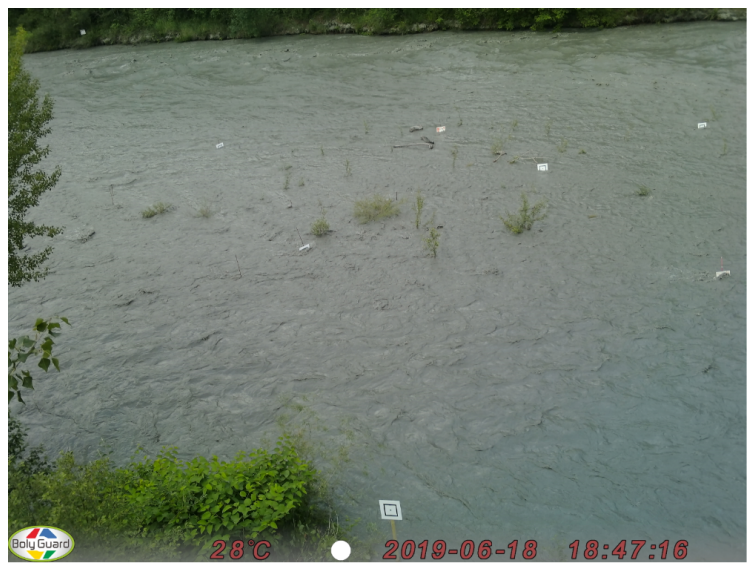

(b)

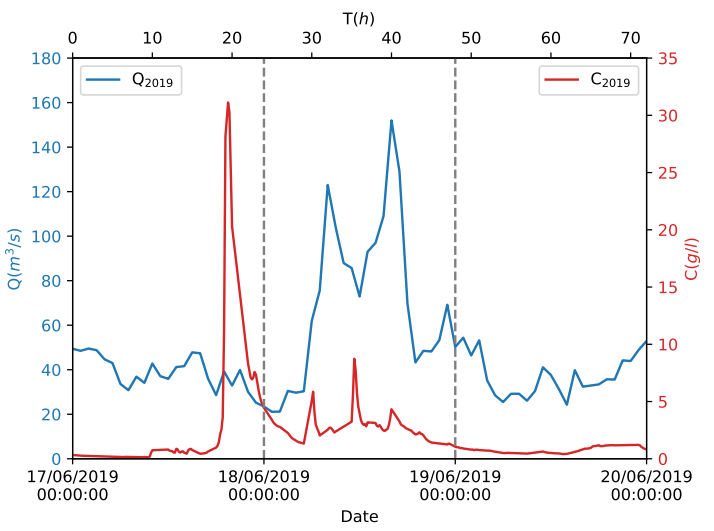

(d)

Figure 2. Photo of the bar before the flushing event in 2019 under a discharge of $47.4 \mathrm{~m}^{3} / \mathrm{s}$ (a), photo of the inundation over the bar during the flushing event (under a discharge of $129 \mathrm{~m}^{3} / \mathrm{s}$ ) (b) and hydrographs and sediment-graphs measured at St-Jean-de-Maurienne hydro-sedimentary station during the flushing event in 2018 (c) and 2019 (d)

happened in patch 1 because it is close to the secondary channel where local bed shear stress is relatively higher (exceed $10 \mathrm{~Pa}$ for the 2015 flush according to, Camenen et al., 2016).

\section{IMAGE DETECTION METHOD}

\subsection{Data collection and pre-processing}

A new image detection method developed for the estimation of the surface deposition of fine sediment on a gravel bed from an image was carried out. A preliminary version was presented by Pénard et al., 2019,. Images were firstly acquired by a time-lapse camera attached on a tree trunk on the top of river bank. They were collected automatically with a frequency of 1 image per 30 minutes during the flushing event and 2 images per day on the other days. The resolution of the camera is approximately $5 \mathrm{~cm}$ for each pixel. The camera was calibrated by fixing the intrinsic/extrinsic parameters. Some field measurements were then carried out including Ground Reference Points (GRPs) and image corresponding points selection to prepare for the image orthorectification. Finally images were orthorectified according to the calibration parameters of camera, GRPs and a Digital Elevation Model (DEM). 


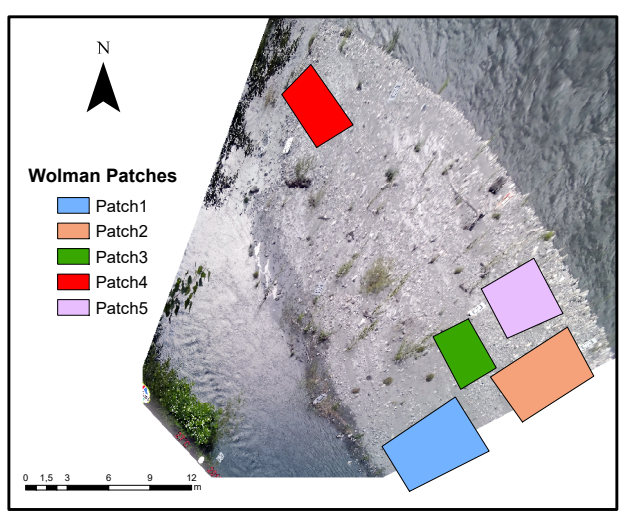

(a)

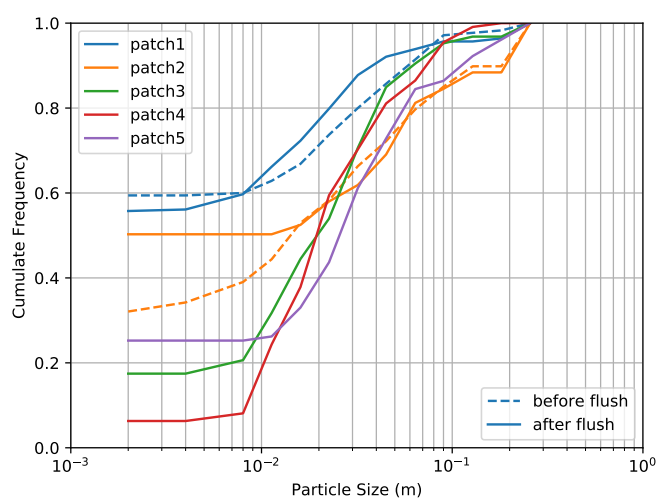

(b)

Figure 3. Location of local sediment measurement (Wolman) patches (a) and Granulometric curves from Wolman peddle count method (b).

\subsection{Bar segmentation}

Once data had been collected and pre-processed, the bar segmentation was conducted to estimate the surface area of fine sediment deposits. The following method is illustrated by Figure 4.

The first step of bar segmentation consisted in sharpening the image to emphasize fine details in the image and to get the pixels representing the fine sediments boosted. Starting from the orthorectified image, the image with RGB (Red, Green, Blue) color space was firstly converted into the HSV (Hue, Saturation, Value) color space. Secondly the Fast Fourier Transform (FFT) was applied to obtain the frequency of the image. Then a high-pass filter on the frequency domain of image was implemented to emphasize the pixels of the fine sediment deposits. Finally the inverted FFT was done on the filtered image and the image was switched back to the HSV image domain.

The second step consisted in segmentation of the image into several clusters minimizing withincluster variances to classify the pixels to represent the deposits of fine sediment. In this step, an algorithm called $K$-means clustering (Lloyd, 1982) was used. Firstly, user decided the number of clusters $K$. Secondly, the $K$-means algorithm created random $K$ values representing the centroid value of each cluster and assigned each pixel to the closest centroid after that the pixels form $K$ clusters. Next, the algorithm computed the variance of each cluster and replace the centroid of each cluster until the algorithm minimized their variance. Finally, the pixels in the first cluster were selected as the fine sediment deposit region. It is noted that the algorithm classified the pixels only taking into account the value of each pixel, whereas the link between the value of pixels in the image and the actual size of sediment was unclear due to the limitation of the image resolution. So this method might lead to a systematic bias when calculating the area of deposits.

The last step was the morphological opening and closing of the resulting region. This step aimed at reshaping the selected region by applying morphological dilation and erosion to have a pertinent region.

\subsection{Validation with Wolman pebble count method}

The Wolman pebble count method was considered as a reference method to validate the reliability of the image detection method. Comparison between the results of these two methods has been conducted for the flush in 2019. It is noted that the Wolman pebble count method provided a volume GSD whereas image detection method provided an areal GSD. To be able to compare results of the two methods, firstly, the Wolman GSD was transformed into the areal GSD by the following equation:

$$
\Phi_{\text {Area }}^{i}=\frac{S_{i}}{\sum S}=\frac{\Phi_{\text {Wolman }}^{i}}{D_{i} \sum S}
$$



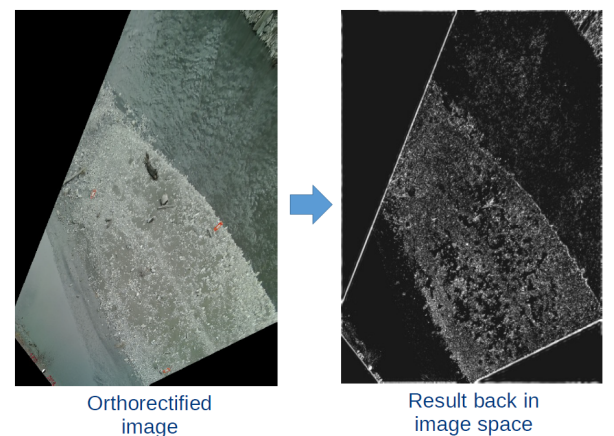

(a)

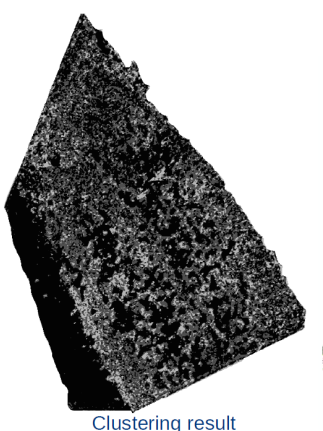

(b)

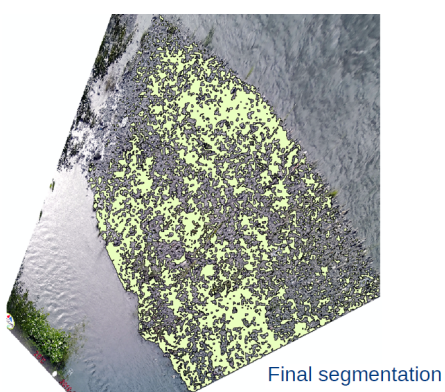

(c)

Figure 4. The first step: High-pass filter on the Fourier transform of the Value channel (a), the second step: $K$-means clustering: segmentation into k clusters minimizing within-cluster variances (b) and the last step: Morphological opening and closing of the resulting regions (c)

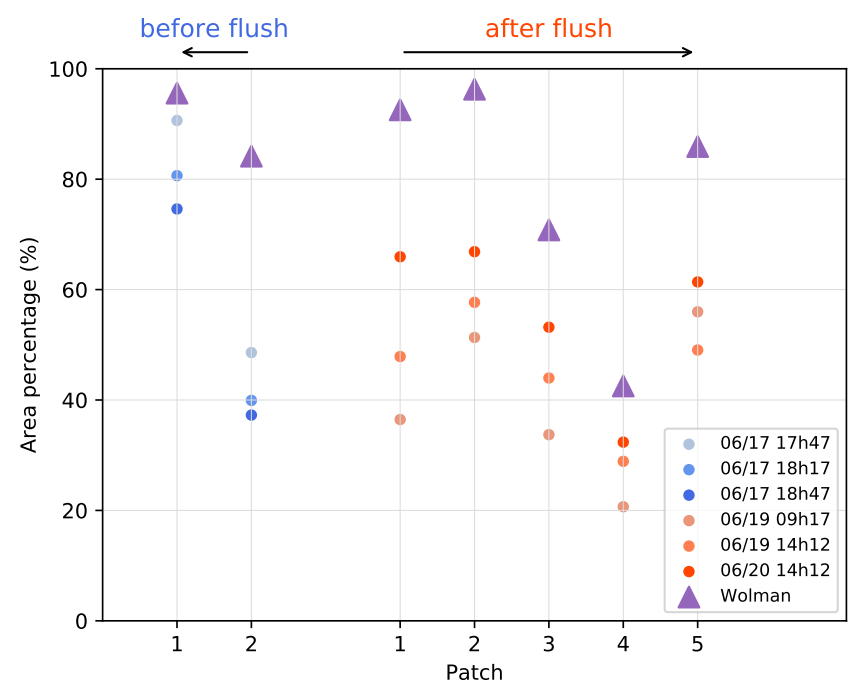

Figure 5. Comparison between Wolman areal percentage and the image areal percentage for the class $D_{i} \leq 2 \mathrm{~mm}$ for the flushing event in 2019 (The average difference between two methods is $40 \%$ ).

where $\Phi_{W o l m a n}^{i}=$ volumetric percentage of class $i$ in Wolman; $D_{i}=$ diameter of class $i$; and $S_{i}$ $=$ areal percentage of class $i$. Secondly, the areal percentage estimated by the image detection method in the Wolman patches was calculated. Finally, the comparison was done for the class $D_{i} \leq 2 \mathrm{~mm}$.

Results are plotted in Figure 5. The spatial variation of fine sediment deposits seems to be successfully produced by both two methods. However, the area percentages of fine sediment deposits for all patches are underestimated by the image detection method. It may be due to the selection of the first class of $K$-means cluster only, that resulted in neglecting the fine sediment deposits from other classes. In addition, the limitation of the pixel size could cause the lack of representation of fine sediment deposits close to the large particles (pebbles or boulders). The pixels of the fine sediment deposition around the pixels of the coarse particles could also be eliminated by the dilation and erosion of mathematical morphological analyse during the image processing. Looking at the percentage from different photos, a non-negligible difference was also noted. This may be due to the time when the photo had been taken causing a difference on the brightness of the photos. This difference on the brightness may lead to a bias when $K$-means clustering. The pixels would be classified in the same cluster because of the brightness but they actually represented different sediments. A future work could be done on the sensitivity of the light and weather conditions when the photo is taken. Concerning Wolman pebble count method, even 
if it was a reference method, it produced a relatively high statistic bias which led to a statistical percent error ( $\pm 20 \%$ for a sample size of 400 particles) for the estimation of $D_{5}$ (Bunte and Abt, 2001), i.e. a significant error on the estimation of fine sediment content. Thus, the bias observed in Figure 5 could either come from the Wolman pebble count method or from image detection method.

\section{ESTIMATION OF FINE SEDIMENT DEPOSIT FOR TWO FLUSHING EVENTS}

The image detection method has been implemented to evaluate the deposit dynamics for the 2018 and 2019 flushing events. One photo before and after flush were selected for each flush. The pixel size for both orthorectified photos is $5 \mathrm{~cm}$ and the bar has been photographed under a similar light condition to minimize the brightness bias. In Figure 6, the direction of the river flow is from the bottom right of the photo to the upper left, the main channel of the river is on the upper right of the photo and the secondary channel is located on the bottom left of the photo.

The surface areas of deposits are presented in Table 1 for the four studied photos. The bar has lost 5.3\% of fine sediment surface area after the 2018 flush and $6.1 \%$ after the 2019 flush, respectively. Figure 6 shows the corresponding maps of distribution of the deposits. Before the 2018 flush, fine sediment deposits were mostly distributed at the tail of the bar and slightly distributed in the zone close to the secondary channel. After the flush, fine sediments at these two positions were mostly washed out and new deposits were found in the middle of the bar. A similar result could be found for the 2019 flush.

To explain this phenomenon, one should mention the existence of a transverse channel delivering water from secondary channel to main channel at the tail of the bar. During the flood, the water depth in the transverse channel grew with the increase of the discharge; high bed shear stresses can thus be observed leading to some erosion in this transverse channel (Camenen et al., 2016). However, in the middle of the bar, due to lower bed shear stresses (low water depth), fine sediment deposits could not be resuspended. For other zones on the bar, it was difficult to explain the dynamic of fine sediment deposits by the bed shear stress. Indeed, a phase-lag between the flushing flood wave and the velocity peak propagation was found in the previous flushing events. This phase-lag caused a complex combination of water depth and velocity distribution, which led to a variation in time of local bed shear stress on the bar and thus complicated the dynamic of fine sediment deposits. Furthermore, a difference between the deposition after the 2018 flush and the deposition before the 2019 flush can also be observed. This could be due to the fact that a natural flood has been taken place on 23 October 2018 with a peak discharge of $163 \mathrm{~m}^{3} / \mathrm{s}$ and a peak concentration of $14.7 \mathrm{~g} / \mathrm{l}$.

Table 1. Results of estimation of fine sediment deposition area for the flush 2018 and 2019.

\begin{tabular}{lllll}
\hline Year & Photo & $S_{\text {bar }}\left(\mathrm{m}^{2}\right)$ & $S_{\text {Dep }}\left(\mathrm{m}^{2}\right)$ & $S_{\text {Dep }} / S_{\text {bar }}(\%)$ \\
\hline 2018 & before & 575.5 & 252,0 & 43.8 \\
& after & 581.7 & 223.8 & 38.5 \\
\hline 2019 & before & 594.5 & 301.1 & 50.6 \\
& after & 587.7 & 261.4 & 44.5 \\
\hline
\end{tabular}

\section{CONCLUSION}

A new image detection method has been validated using local field measurements and implemented on a gravel bar to evaluate the fine sediment deposit dynamic after two hydrological flushing events. A validation with Wolman pebble count method showed that image detection method produced a good agreement on the estimation of spatial distribution of fine deposits on the bar. However, an averaged $40 \%$ underestimation was found. This underestimation was, from the side of the image detection method, due to the bias of the image processing and the limitation of pixel size, and from the side of the Wolman pebble count method, due to a relatively high 


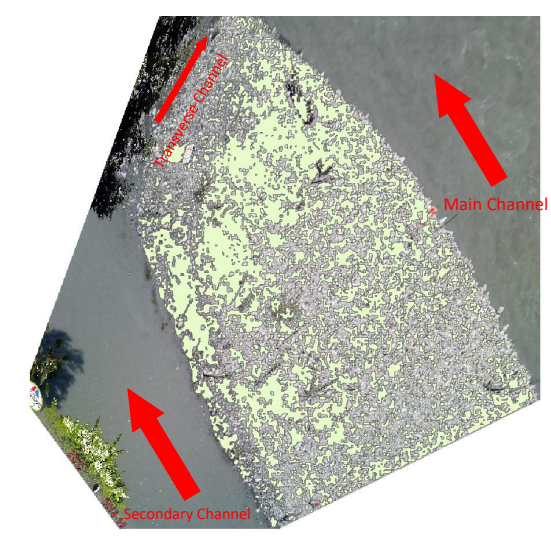

(a)

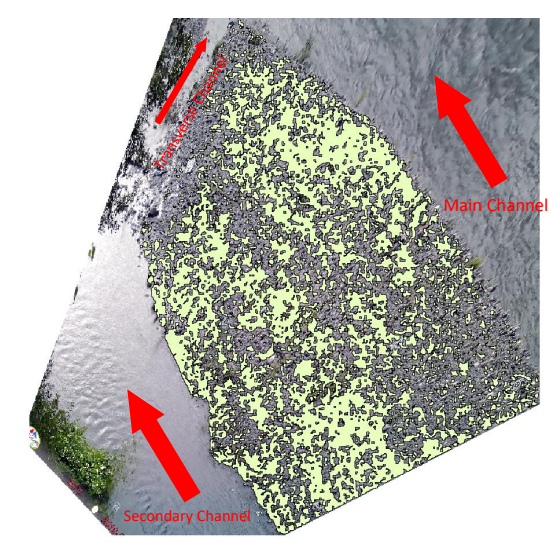

(c)

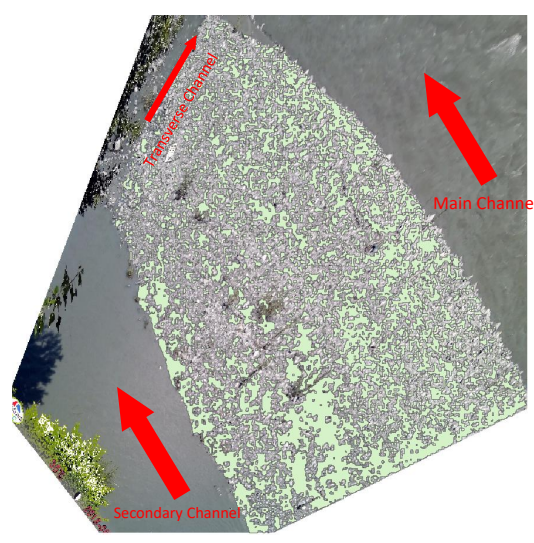

(b)

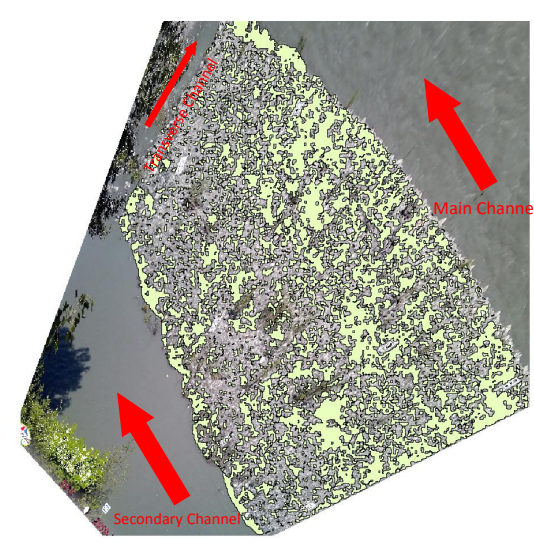

(d)

Figure 6. The map of deposit before (a) and after (b) the flush in 2018 and the map of deposit before (c) and after (d) the flush in 2019 estimated by the image detection method.

statistical percent error when estimating the fine sediment content. A variation of the results from different photos taken a priori while the surface deposit distribution was the same indicated that the method might be sensitive to the brightness of the input photos.

The image detection method has been used to evaluate the dynamics of fine sediment after two flushing events (2018 and 2019). The results showed that some erosion took place at the tail of the bar and on the right side of the secondary channel for both two flushing events. As observed by Camenen et al., 2016, the phase-lag between water depth and velocities on the bar makes the understanding of the fine sediment dynamics complicated to explain by just looking at the local bed shear stresses. One perspective will be the implementation of the image detection method on the photo time series (during several years) to be able to compare the dynamics of fine sediments for different hydrological events and also to link the dynamic of fine sediment with other factors such as rainfall intensity and wind, which could have an impact on the fine sediment deposits on the bar.

\section{ACKNOWLEDGEMENTS}

This study was supported by Irstea and EDF-CIH (Electricité De France - Centre d'Ingénierie Hydraulique) and by the French National Research Agency (ANR) under the grant ANR-18CE01-0020 DEAR Project. 


\section{REFERENCES}

Antoine, G. (2013). Dynamique des matériaux en suspension le long de rivières aménagées de montagne. Exemple de l'Arc en Maurienne et de l'Isère [Suspended sediment dynamics along engineered alpine rivers. Exemple of the Arc en Maurienne and Isère rivers]. PhD thesis, Grenoble University, Grenoble, France. 282 p. (in French).

Antoine, G., Jodeau, M., Camenen, B., Esteves, M., Némery, J., and Lauters, F. (2013). Estimation des flux de matières en suspension lors des chasses hydrauliques de l'Arc de 2006 à 2011. La Houille Blanche, 4:43-49. (in French).

Bridge, J. S. (1993). Description and interpretation of fluvial deposits: a critical perspective. Sedimentology, 40(2):801-810.

Bunte, K. and Abt, S. R. (2001). Sampling surface and subsurface, particle-size distributions in wadable gravel- and cobble-bed streams for analyses in sediment transport, hydraulics, and streambed monitoring. General Technical Report RMRS-GTR-74, United State Department of Agriculture, Forest service, Rocky Mountain Research Station, Fort Collins, Colorado, USA. 430 p.

Camenen, B., Dramais, G., Buffet, A., Thollet, F., Le Bescond, C., Lagouy, M., Berni, C., and Le Coz, J. (2018). Estimation of sand suspension in a secondary channel of an alpine river. In Paquier, A., Rivière, N., and Khaladi, A., editors, River Flow, Proc. 9th Int. Conf. on Fluvial Hydraulics, number 04014 in E3S Web of Conferences 40, pages 1-8, Lyon, France.

Camenen, B., Herrero, A., Dramais, G., Thollet, F., Le Bescond, C., Perret, E., and Berni, C. (2015). Field experiment on the dynamics of fine sediments over a gravel bar in an alpine gravel-bed river. In 9th IAHR symposium on River, Coastal and Estuarine Morphodynamics, page 4p., Iquitos, Peru.

Camenen, B., Herrero, A., Perret, E., Berni, C., Thollet, F., Buffet, A., Dramais, G., Le Bescond, C., and Lagouy, M. (2016). Estimation of the volume of a fine sediment deposit over a gravel bar during a flushing event. In River Flow, Proc. 8th Int. Conf. on Fluvial Hydraulics, page 8p., St Louis, Missouri, USA.

Camenen, B., Jodeau, M., and Jaballah, M. (2013). Estimate of fine sediment deposit dynamics over a gravel bar using photography analysis. International Journal on Sediment Research, 28(2):220-233.

Jaballah, M., Camenen, B., Paquier, A., and Jodeau, M. (2015). Alternate bar development in an alpine river following engineering works. Advances in Water Resources. (in revision).

Lloyd, S. (1982). Least squares quantization in pcm. IEEE Transactions on Information Theory, 28(2):129137.

Misset, C., Recking, A., Legout, C., Valsangkar, N., Bodereau, N., Zanker, S., Poirel, A., and Borgniet, L. (2019). The dynamics of suspended sediment in a typical alpine alluvial river reach: Insight from a seasonal survey. Water Resources Research, pages 1-17.

Pénard, L., Drevet, T., Vergne, T., Deng, J., and Camenen, B. (2019). Image-based fine sediment detection on gravel bars surface. In 11th IAHR symposium on River, Coastal and Estuarine Morphodynamics.

Wolman, M. G. (1954). A method of sampling coarse river-bed material. Transactions of the American Geophysical Union, 35(6):951-956. 